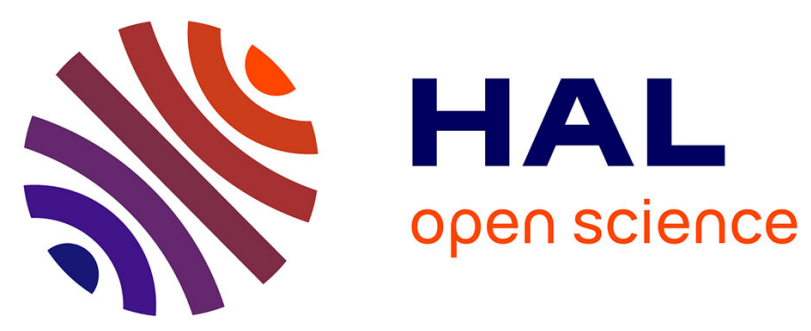

\title{
Mechanisms of deformation in crystallizable natural rubber. Part 1: Thermal characterization
}

J. R. Samaca Martinez, J.-B. Le Cam, Xavier Balandraud, Evelyne Toussaint, J. Caillard

\section{- To cite this version:}

J. R. Samaca Martinez, J.-B. Le Cam, Xavier Balandraud, Evelyne Toussaint, J. Caillard. Mechanisms of deformation in crystallizable natural rubber. Part 1: Thermal characterization. Polymer, 2013, 54 (11), pp.2717-2726. 10.1016/j.polymer.2013.03.011 . hal-01073889

\section{HAL Id: hal-01073889 \\ https://hal.science/hal-01073889}

Submitted on 11 May 2020

HAL is a multi-disciplinary open access archive for the deposit and dissemination of scientific research documents, whether they are published or not. The documents may come from teaching and research institutions in France or abroad, or from public or private research centers.
L'archive ouverte pluridisciplinaire HAL, est destinée au dépôt et à la diffusion de documents scientifiques de niveau recherche, publiés ou non, émanant des établissements d'enseignement et de recherche français ou étrangers, des laboratoires publics ou privés. 


\title{
Mechanisms of deformation in crystallizable natural rubber. Part 1: Thermal characterization
}

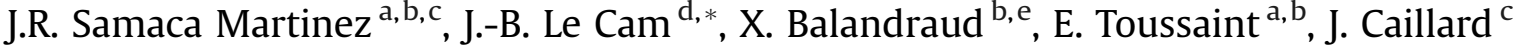 \\ ${ }^{a}$ Clermont Université, Université Blaise Pascal, Institut Pascal, BP 10448, 63000 Clermont-Ferrand, France \\ ${ }^{\mathrm{b}}$ CNRS, UMR 6602, Institut Pascal, 63171 Aubière, France \\ ${ }^{c}$ Michelin, cerl Ladoux, 63040 Clermont-Ferrand, France \\ d Université de Rennes 1, Larmaur ERL CNRS 6274, Campus de Beaulieu, 35042 Rennes, France \\ ${ }^{e}$ Clermont Université, Institut Français de Mécanique Avancée, Institut Pascal, BP 10448, 63000 Clermont-Ferrand, France
}

This paper investigates the mechanisms of deformation in rubber, especially stress-induced crystallization, using infrared thermography. Temperature variations are measured during cyclic uniaxial mechanical tests at ambient temperature. Results show that natural rubber mainly exhibits entropic behaviour: the material produces (resp. absorbs) heat during loading (resp. unloading). The crystallization of the polymer chains under tension leads to a temperature increase of the order of several degrees Celsius. If crystallization and crystallite melting occur over one mechanical cycle, a hysteresis loop is observed in terms of the strain-stress relationship. Stress relaxation tests show that the thermal signatures of crystallization and of crystallite melting are different. Indeed, if the strain is maintained fixed during loading, the temperature continues to increase for a few seconds before returning to the ambient temperature. This reveals that crystallization continues during relaxation. On the contrary, if the strain is maintained fixed during unloading, the specimen returns instantaneously to the ambient temperature.

\section{Introduction}

Elastomers are widely used in many fields, such as mechanical engineering, automotive engineering and aerospace engineering, due to their high elasticity, high damping and high elongation at failure. Such materials are subjected to many phenomena that take place during the deformation processes. Most of these phenomena are still not clearly understood: the Mullins effect [1,2], the Payne (or Fletcher-Gent) effect [3,4], cavitation [5-7], stress-induced crystallization [8-15] and possible couplings between them.

Classically, rubber-like elasticity is described as an entropic phenomenon, which leads to heat production during loading and heat absorption during unloading. This was first observed by Refs. $[16,17]$. In spite of these results, no further experimental study was dedicated to the thermomechanical characterization of elastomers, although this is a key point for the understanding of the above

\footnotetext{
* Corresponding author. Tel.: +3322323 57 41; fax: +33223236111.

E-mail address: jean-benoit.lecam@univ-rennes1.fr (J.-B. Le Cam).
}

mentioned phenomena as well as the phenomena involved in fatigue damage [18-21].

From an experimental point of view, full-field measurement techniques have increasingly been used since the 1980s to study the deformation processes of materials. These techniques provide surface measurements without any contact with the specimen under study. In particular, infrared (IR) cameras are used to capture temperature fields. This technique has been widely applied to metals, polymers and composite materials (see for instance Refs. [22-24]), but rarely to elastomeric materials [25-27]. The present paper aims at analysing the temperature variations obtained by IR thermography during the deformation of natural rubber in order to characterize the thermal response of such crystallizable rubber under mechanical loadings. One of the main issues is to link the changes in the microstructure, which occur at the microscopic scale, to the corresponding temperature variation measured at the macroscopic scale.

Section 2 presents the experimental setup, i.e. the material, the specimen geometry, the loading conditions and the measurement device. Section 3 gives the results obtained for cyclic and relaxation 
tests by associating mechanical and thermal responses. Finally, a conclusion recalls the main results of the paper and presents the perspectives that will be developed in the second part of the present study (see Samaca Martinez et al. [28]).

\section{Experimental setup}

\subsection{Material and specimen geometry}

The material considered here is an unfilled natural rubber. It is denoted NR in the following. Its chemical composition is given in Table 1 . The compound was cured for $22 \mathrm{~min}$ at $150{ }^{\circ} \mathrm{C}$. The degree of crosslinking is $6.5 \cdot 10^{-5} \mathrm{~mol} \mathrm{~cm}{ }^{-3}$. This material was chosen in order to study the thermal response of the macromolecular network without interaction between the rubber matrix and the fillers. Moreover, this type of material is subject to strain-induced crystallization and it is therefore relevant to characterize the thermal signature of such a phenomenon.

In NR, the crystallization of the polymer chains is observed in uniaxial tension starting from a stretch ratio, defined as the ratio between current length and the initial length, of about $\lambda=4$. During unloading, crystallite melting should be complete at a lower stretch ratio, typically equal to about $\lambda=3[6,8,11]$. In the following, these stretch ratios at which crystallization begins and at which crystallite melting is complete are denoted $\lambda_{c}$ and $\lambda_{\mathrm{m}}$, respectively.

The specimen tested has a typical dumbbell shape. It is a $5 \mathrm{~mm}$ width, $10 \mathrm{~mm}$ height and $1.4 \mathrm{~mm}$ thick specimen, and is used for uniaxial tensile tests. Its width was chosen to ensure that the strain and stress fields are homogeneous, thus corresponding to a uniaxial tension state.

\subsection{Loading conditions}

Mechanical loadings were applied using a 50 N INSTRON 5543 testing machine. Two types of tests were carried out under imposed displacement:

- the first test corresponds to four sets of three cycles, for four increasing maximum stretch ratios: $\lambda_{1}=2, \lambda_{2}=5, \lambda_{3}=6$ and $\lambda_{4}=7.5$ (see Fig. 1 (a)). $\lambda_{1}$ was chosen inferior to $\lambda_{c}, \lambda_{2}$ was close to $\lambda_{\mathrm{c}}$ and $\lambda_{3}$ and, $\lambda_{4}$ are superior to $\lambda_{\mathrm{c}}$ ( $\lambda_{4}$ is close to the failure stretch ratio). The signal shape chosen was triangular, to ensure a constant strain rate during loading and unloading. In order to observe the effect of the strain rate on the temperature variations, two loading rates were chosen: $\pm 100 \mathrm{~mm} / \mathrm{min}$ and $\pm 300 \mathrm{~mm} / \mathrm{min}$. These conditions correspond to classic tests performed for rubber characterization.

- the second test consists of applying only one mechanical cycle, including pauses of $30 \mathrm{~s}$ at the stretch ratios used for the first type of test, i.e. $\lambda_{\mathrm{i}}$ for $i=1 \ldots 4$, during both loading and unloading (see Fig. 1 (b)). The loading rate was set to $\pm 300 \mathrm{~mm} / \mathrm{min}$.

Table 1

Chemical composition in parts per hundred rubber (phr).

\begin{tabular}{ll}
\hline Ingredient & Quantity \\
\hline Natural rubber NR & 100 \\
Carbon black & 0 \\
Antioxidant 6PPD & 1.9 \\
Stearic acid & 2 \\
Zinc oxide ZnO & 2.5 \\
Accelerator CBS & 1.6 \\
Sulphur solution 2H & 1.6 \\
\hline
\end{tabular}

This test aims at evaluating the effect of the stretch ratio level on stress relaxation through the thermal response, during both the loading and the unloading phases.

\subsection{Temperature field measurements}

Temperature measurements were performed using a Cedip Jade III-MWIR infrared camera, which features a local plane array of $320 \times 240$ pixels and detectors with a wavelength range of 3.5$5 \mu \mathrm{m}$. The integration time is $1500 \mu \mathrm{s}$ and the acquisition frequency $f_{\mathrm{a}}$ is $147 \mathrm{~Hz}$. The thermal resolution, namely the noise-equivalent temperature difference, is equal to $20 \mathrm{mK}$ for a temperature range of $5-40{ }^{\circ} \mathrm{C}$. The calibration of the camera detectors was performed using a black body and using a Non-Uniformity Correction (NUC) procedure. Such a calibration procedure considers the response of the detectors as linear with the radiation flux within a certain temperature range. A so-called two-point calibration was applied using a black body, in order to obtain the offset and the gain for each detector. In order to ensure that the internal temperature of the camera was stabilized before performing the calibration and the measurement, it was switched on $4 \mathrm{~h}$ before the beginning of the experiments. The stabilization of the internal temperature of the camera is necessary to avoid any measurement drift during the tests.

During the measurement, the external heat sources were reduced by using a black box surrounding the specimen, featuring a small window for the IR camera to be able to observe the gauge zone of the specimen (see the overview of the experimental setup in Fig. 2). The temperature fields obtained were filtered using an averaging filter. The thermal quantity considered in the present study is the mean temperature variation of a small zone at the centre of the specimen (see Fig. 3). This quantity is obtained by subtracting the initial temperature from the current one, after applying a suitable movement compensation technique, described in subsection 2.4 .

\subsection{Movement compensation technique}

Since the specimen undergoes large deformations, any given material point at its surface significantly moves during material deformation while the zone captured by the detector array of the infrared camera remains fixed. A correspondence between the geometry of the coupon at any stage of the loading and the reference geometry must therefore be performed to correctly analyse and process the temperature field. This consideration has recently been addressed for various materials [25,27,29-32]. In the present case, the specimen response is considered as thermally homogeneous, due to the very low thermal conductivity of rubber. Nevertheless, for the sake of strictness, it was chosen to track a small zone (5px X $5 \mathrm{px}$ square located at the middle of the gauge length) during the test. As illustrated in Fig. 3, the movement of this zone is taken into account in order to associate a temperature with the material zone at any time of the test. The displacement of the moving grip is directly measured from the thermal images. A linear relationship between the coordinates of the top moving grip and those of the considered zone allows us to directly calculate the displacement of the former.

\section{Results}

In this section, results obtained during the two tests, i.e. the cyclic and the stress relaxation tests are reported. For each test, the mechanical and thermal responses of the specimen are measured and analysed. 


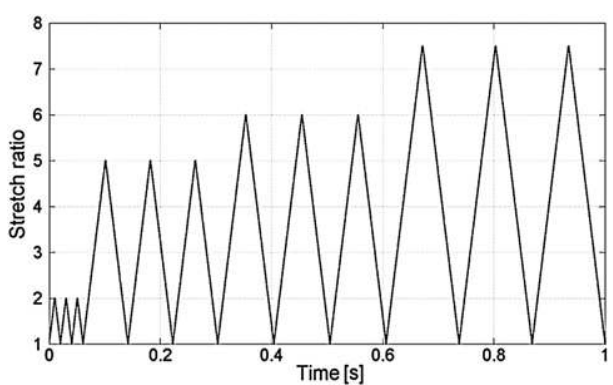

(a) Cyclic test

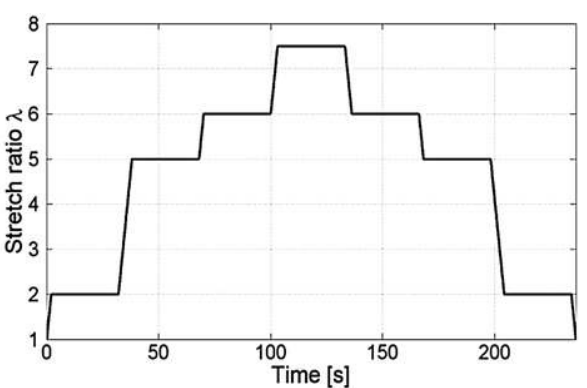

(b) Loading-unloading test with relaxation steps

Fig. 1. The two mechanical loading conditions.

\subsection{Cyclic test}

\subsubsection{Mechanical response}

Results obtained at $\pm 100 \mathrm{~mm} / \mathrm{min}$ and $\pm 300 \mathrm{~mm} / \mathrm{min}$ are presented in Fig. 4 (a) and (b), respectively. These figures present the nominal stress, defined as the force per initial surface ratio, versus the stretch ratio. Firstly, it can be observed that the mechanical cycles have no effect on the mechanical response, in the sense that no stress softening is observed between cycles. Secondly, the loading rate has no effect for low strain levels, but seems to influence the response at higher strain levels (see the change in the curve slope starting from a stretch ratio equal to about 6 ). For these higher strain levels, the higher the loading rate, the higher the nominal stress.

In order to detail more precisely each mechanical cycle, Fig. 5 (a), (b), (c) and (d) give the curves for $\lambda_{1}=2, \lambda_{2}=5, \lambda_{3}=6$ and $\lambda_{4}=7.5$, respectively, and for the two loading rates chosen. Each case exhibits a specific response:

(i) for cycles at $\lambda_{1}=2$ and $\lambda_{2}=5$ : the loading rate has no significant effect on the mechanical response. For both loading rates, no hysteresis loop is observed.

(ii) for cycles at $\lambda_{3}=6$ : the loading rate has a small effect on the mechanical response. A hysteresis loop is formed. The stress

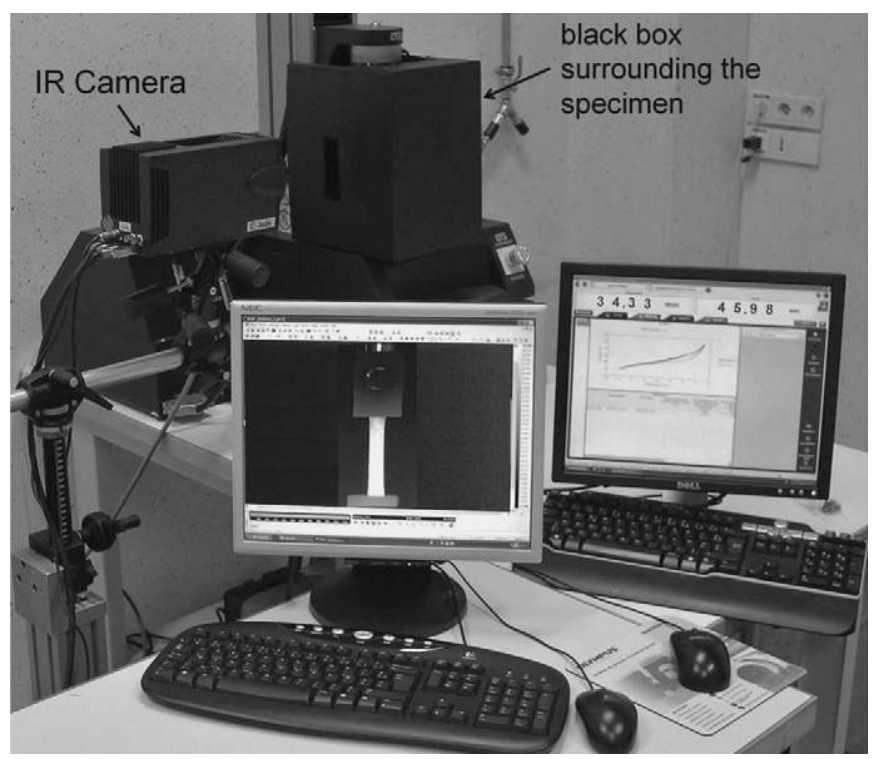

Fig. 2. Overview of the experimental setup. difference tends to disappear for a stretch ratio equal to 3 . These results are in good agreement with those reported in the literature for unfilled natural rubber. The hysteresis loop is explained by the difference in the kinetics of crystallization and crystallite melting $[6,8,11]$. If the stretch ratio applied exceeds the stretch ratio at which crystallization occurs (around 4 for natural rubber), a hysteresis loop begins to form. In fact, this is because crystallization takes place in the bulk material and the crystallinity rate is low compared to the crystallite melting rate (commonly assumed to be instantaneous for a given stretch ratio).

(iii) for cycles at $\lambda_{4}=7.5$ : the effect of the loading rate is more significant from $\lambda=6$ on. The higher the loading rate, the higher the nominal stress at a given stretch ratio. A plateau is observed from $\lambda=6$ on, followed by a high stress increase. The plateau length is smaller for $\pm 300 \mathrm{~mm} / \mathrm{min}$ than for $\pm 100 \mathrm{~mm} / \mathrm{min}$. As explained in Refs. [8,11], once crystallization occurs, relaxation is induced in the amorphous phase. As a consequence, a plateau forms. For higher stretch ratio levels, crystallites act as fillers and strongly reinforce the material stiffness, which explains the high increase in the nominal stress. As for the previous cycles at $\lambda_{3}=6$, the hysteresis loop closes at around $\lambda=3$, which is close to the stretch ratio at which crystallite melting is assumed to be complete.

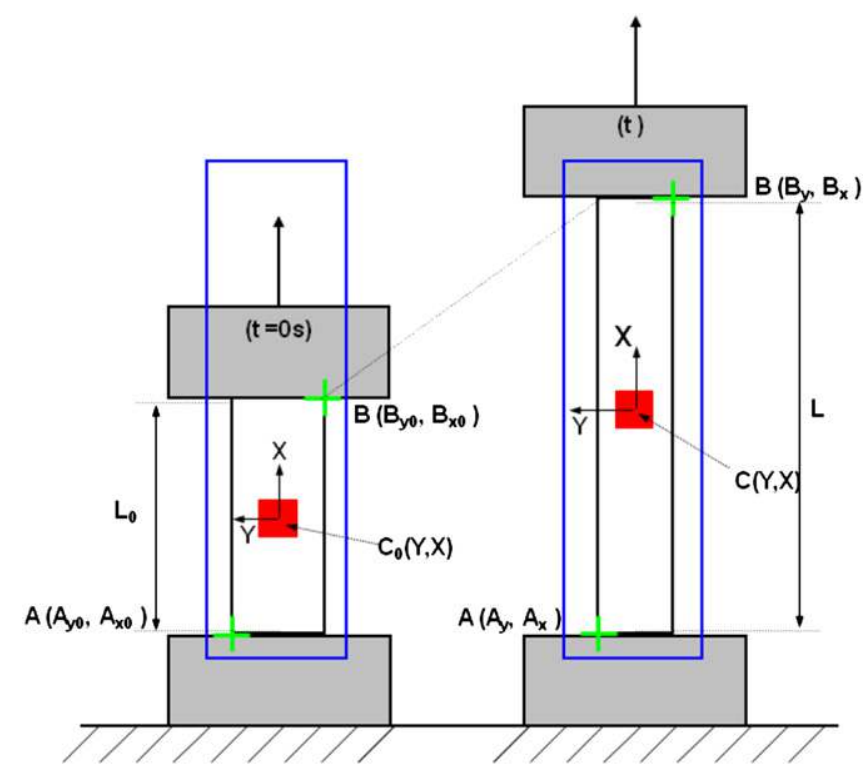

Fig. 3. Movement compensation illustration. 


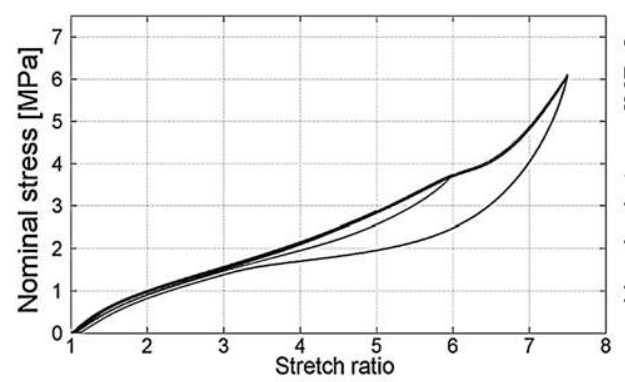

(a) $100 \mathrm{~mm} / \mathrm{min}$ loading rate

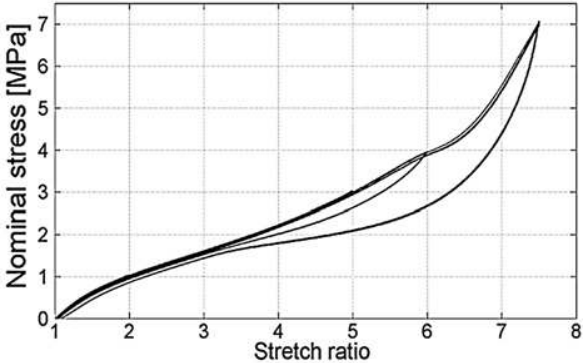

(b) $300 \mathrm{~mm} / \mathrm{min}$ loading rate

Fig. 4. Mechanical cycles at four increasing stretch ratios.

\subsubsection{Thermal response}

The thermal response of the specimen was measured during the mechanical test. The aim of such a measurement is two fold. The first objective is to characterize the thermal response of rubber during a classic mechanical test. The second objective is to highlight the effects of the loading rate and the number of cycles on the thermal response.

Fig. 6 gives the temperature variations $\theta$ obtained during the test: Fig. 6 (b) for $\pm 100 \mathrm{~mm} / \mathrm{min}$ and Fig. 6 (c) for $\pm 300 \mathrm{~mm} / \mathrm{min}$. Some preliminary comments can be made from these curves. First, it is observed that the temperature variation oscillates at the same frequency as the load. Second, inside each set of three cycles at a given maximum stretch ratio, the maximum temperature variation slightly decreases (this is more visible at $\pm 300 \mathrm{~mm} / \mathrm{min}$ than at $\pm 100 \mathrm{~mm} / \mathrm{min}$ ). Third, during the loading phases of the last two sets of three cycles (at $\lambda_{3}=6$ and $\lambda_{4}=7.5$ ), a sudden change in the temperature variation rate is observed. In order to understand this thermal response, the contribution of the heat exchanges with the outside of the specimen (level of non-adiabaticity of the evolution) must be taken into account. Results are detailed and commented in the following paragraph for each loading step.
Fig. 7 presents the temperature variation $\theta$ obtained for the first set of three cycles $\left(\lambda_{1}=2\right)$ ). Fig. 7 (a) shows the temperature variation during the three cycles for a loading rate equal to $\pm 100 \mathrm{~mm} / \mathrm{min}$. It can be noted that time (in abscissa) has been initialized at the beginning of each cycle. At the first cycle, during the loading phase, the temperature variation first decreases before increasing. This is a well-known phenomenon in rubbery materials [17], which is explained by the competition between the effects of internal energy variation and entropy variation with respect to the strain level. At low strain levels, temperature variation is governed by the variation of the internal energy (negative heat source for a positive strain rate): so a small temperature decrease is first observed. At higher strain levels, temperature variation is governed by entropic coupling (positive heat source for a positive strain rate): so a temperature increase is then observed. This leads to the occurrence of the so-called thermoelastic inversion, here close to $\lambda=1.1$. Obviously, this phenomenon is also observed during unloading. It can be also noted that the temperature variation at the end of the first cycle is inferior to that at the beginning of the cycle, so a shift in the curve position is observed between the cycles. Similar observations can be made for the higher loading rate

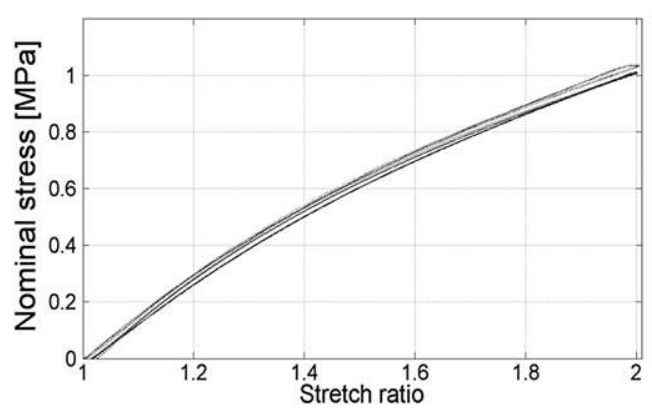

(a) $\lambda_{1}=2$

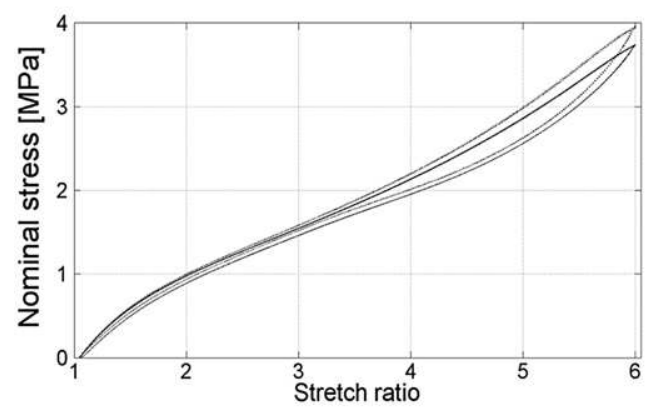

(c) $\lambda_{3}=6$

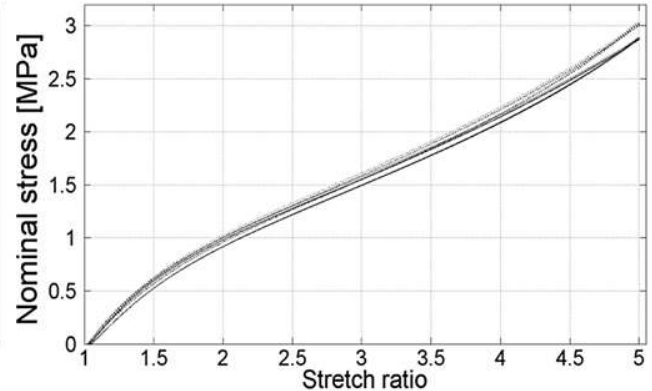

(b) $\lambda_{2}=5$

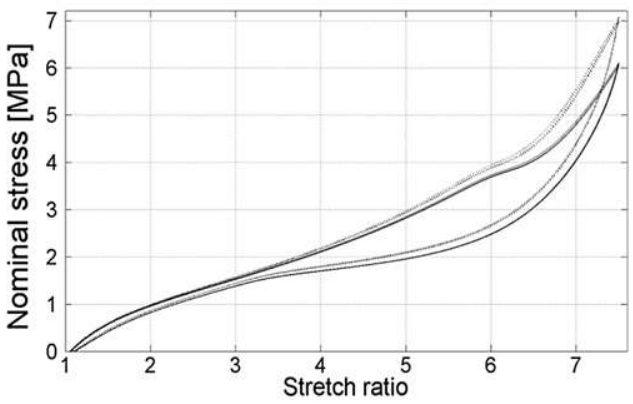

(d) $\lambda_{4}=7.5$

Fig. 5. Three mechanical cycles at four increasing stretch ratios and for both $\pm 100 \mathrm{~mm} / \mathrm{min}$ (solid line) and $\pm 300 \mathrm{~mm} / \mathrm{min}$ (dotted line) loading rates. 


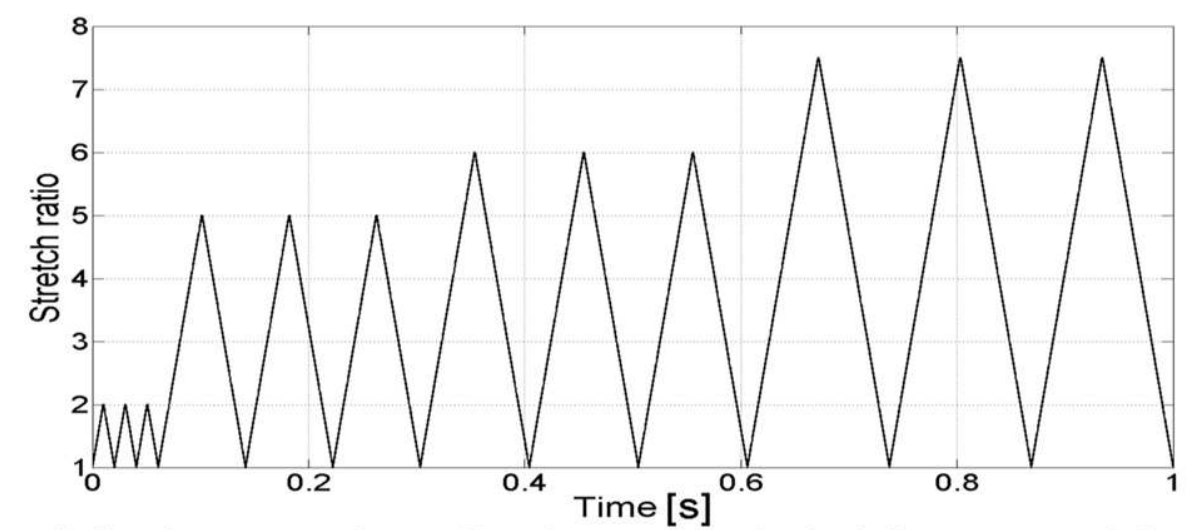

(a) Stretch ratio versus the time. Here, the time is normalized to be homogeneous with the time scale in Figure 7(b) and Figure 7(c), due to the two loading rates applied.

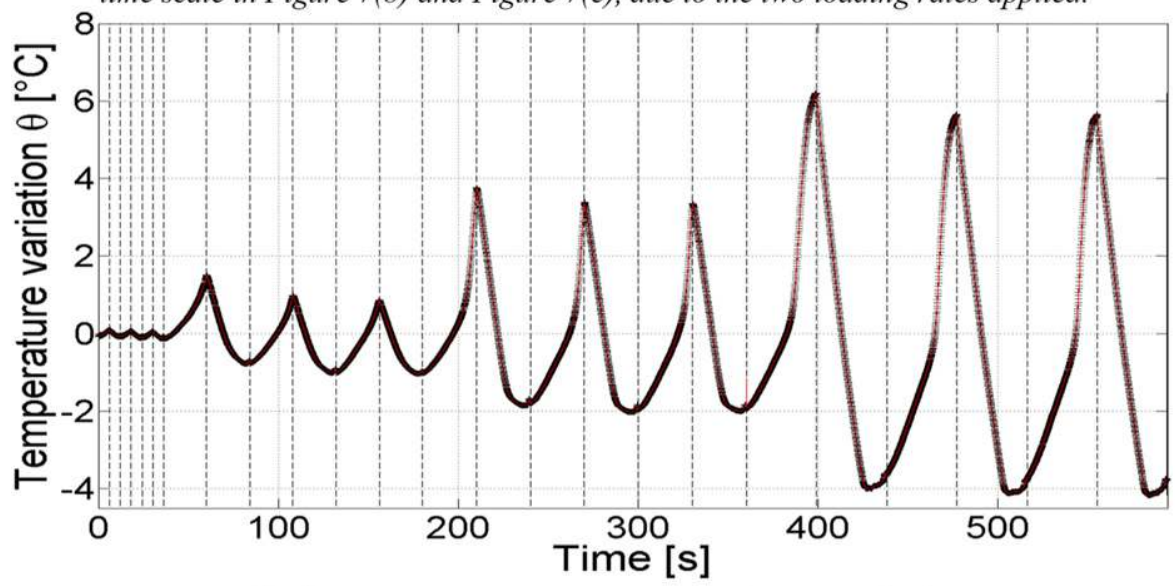

(b) Temperature variation versus time $( \pm 100 \mathrm{~mm} / \mathrm{min})$

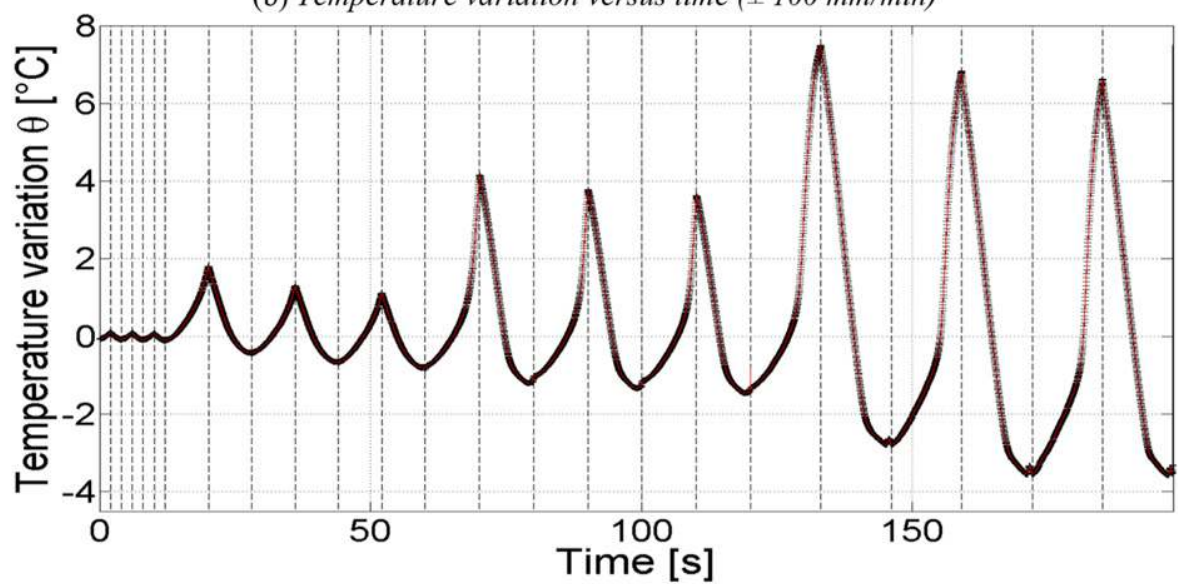

(c) Temperature variation versus time $( \pm 300 \mathrm{~mm} / \mathrm{min})$

Fig. 6. Thermal response of the specimen for two loading rates.

( $\pm 300 \mathrm{~mm} / \mathrm{min}$, see Fig. 7 (b)), but the amplitude of the shift is lower than for $\pm 100 \mathrm{~mm} / \mathrm{min}$.

All these observations can easily be explained by considering the heat exchanges with the outside of the specimen (mainly the ambient air). For this purpose, Fig. 8 allows us to explain more precisely the effects of the non-adiabaticity conditions on the thermal response. This figure illustrates the temperature variation $\theta$ for adiabatic (dotted line) and non-adiabatic (solid line) conditions versus time. The model does not account for the thermal inversion. Consequently, the heat source $s$ is positive during loading and negative during unloading:
- Loading phase: As the heat source $s$ is positive, the material temperature increases, leading to a temperature higher than the ambient temperature value $(\theta>0)$. Segments $\left[\mathrm{AB}^{\prime}\right]$ and $[A B]$ give the temperature variations for adiabatic and nonadiabatic conditions, respectively. For the non-adiabatic case, the material gives heat to the ambient air (because it is warmer than the ambient air). This explains why $\theta$ at point $B$ is inferior to $\theta$ at point $\mathrm{B}^{\prime}$.

- Unloading phase: The heat source $s$ is negative, leading to a temperature decrease. Segment $\left[\mathrm{B}^{\prime} \mathrm{C}^{\prime}\right]$ corresponds to the continuation of the adiabatic evolution. As the heat absorbed 


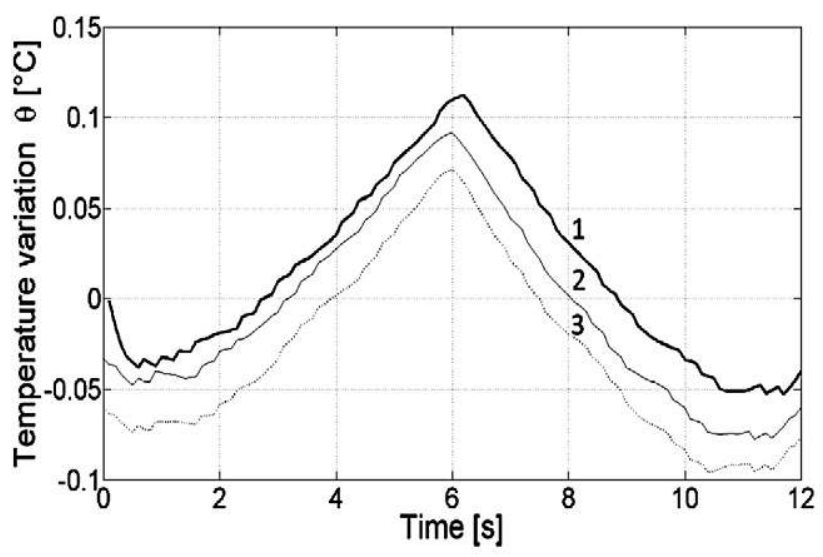

(a) Temperature variation during the three cycles at $\pm 100 \mathrm{~mm} / \mathrm{min}$

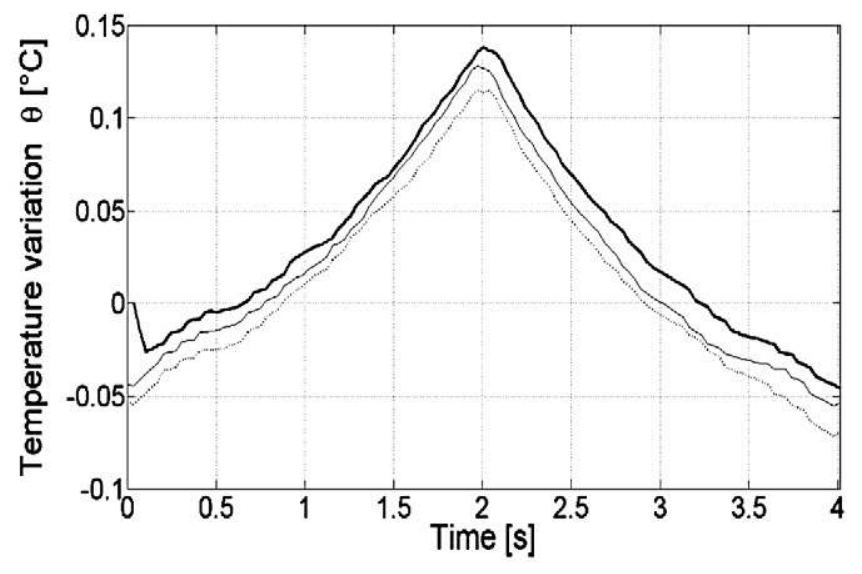

(b) Temperature variation during the three cycles at $\pm 300 \mathrm{~mm} / \mathrm{min}$

Fig. 7. Temperature variation for three cycles at $\lambda_{1}=2$ for two loading rates. Solid thick line $=$ cycle 1 , solid thin line $=$ cycle 2 , dotted line $=$ cycle 3 .

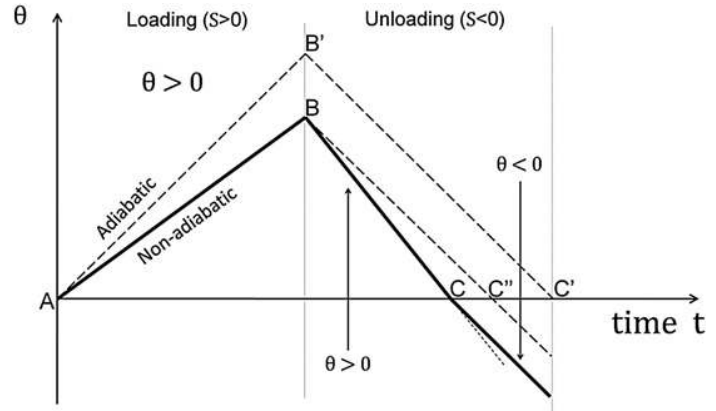

Fig. 8. Modelling of the effect of the non-adiabaticity on the thermal response. Adiabatic condition (dotted line), non-adiabatic condition (solid line).

during unloading is equal to the heat which was produced during loading, the temperature returns to the initial value at the end of the cycle: $\theta\left(C^{\prime}\right)=0$. If adiabatic conditions were applied from point $\mathrm{B}$, the temperature at the end of the cycle would of course be negative: $\theta=0$ would be reached before the end of the cycle (point $C^{\prime \prime}$ ). Let us examine now the actual evolution from point $B$. In the first unloading phase, the temperature is higher than the ambient temperature $(\theta>0)$, so the material continues to give heat to the outside (because it is warmer than the ambient air). This leads to a more rapid return to ambient temperature than for adiabatic conditions (see segment $[\mathrm{BC}])$. In the second unloading phase, the temperature is lower than the ambient temperature $(\theta<0)$, so the material receives heat from the outside (because it is colder than the ambient air). This leads to a change in the slope of the curve.

In conclusion, Fig. 8 enables us to simply explain the temperature evolution presented in Fig. 7.

Fig. 9 presents the temperature variations obtained for the second set of three cycles $\left(\lambda_{2}=5\right)$. As in the previous case, the time scale has been initialized at the beginning of each cycle. Fig. 9 (a) shows the temperature variation obtained during the three cycles for a loading rate equal to $\pm 100 \mathrm{~mm} / \mathrm{min}$. Two comments can be made from this figure. First, the maximum temperature variation is greater than previously (about $1.5^{\circ} \mathrm{C}$, to be compared to $0.1{ }^{\circ} \mathrm{C}$, see Fig. 7 (a)). Second, it can be seen that stabilized evolution is reached from the third cycle (same temperatures at the beginning and the end of the third cycle). This can be simply explained by the fact that the cycle lasts longer. These observations are similar for a loading rate equal to $\pm 300 \mathrm{~mm} / \mathrm{min}$ (Fig. 9 (b)), except that the stabilized regime is not reached after three cycles (different temperatures at the beginning and at the end of the third cycle). This is explained by the fact that the material did not have enough time to reach the stabilized regime (the cycles are three times shorter than at

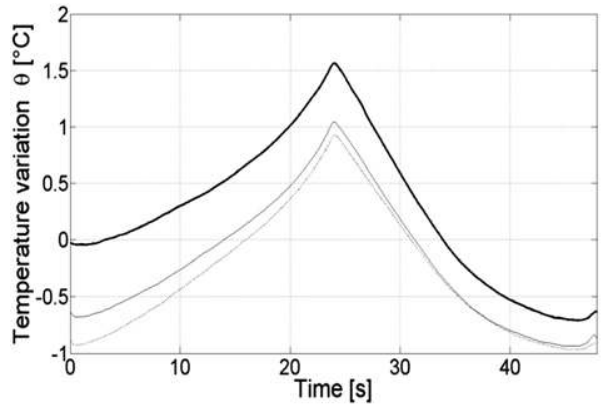

(a) Temperature variation during the three cycles at $\pm 100 \mathrm{~mm} / \mathrm{min}$

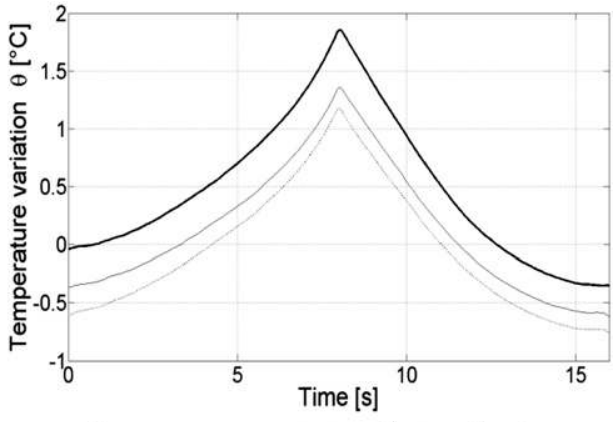

(b) Temperature variation during the three cycles at $\pm 300 \mathrm{~mm} / \mathrm{min}$

Fig. 9. Temperature variation for three cycles at $\lambda_{2}=5$ for two loading rates. Solid thick line $=$ cycle 1 , solid thin line $=$ cycle 2 , dotted line $=$ cycle 3 . 


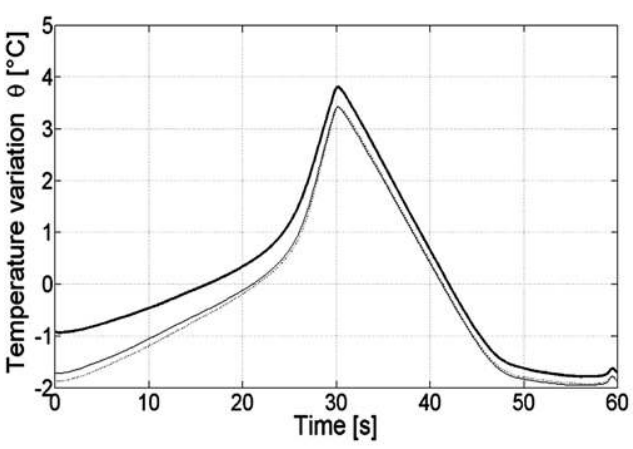

(a) Temperature variation during the three cycles at $\pm 100 \mathrm{~mm} / \mathrm{min}$

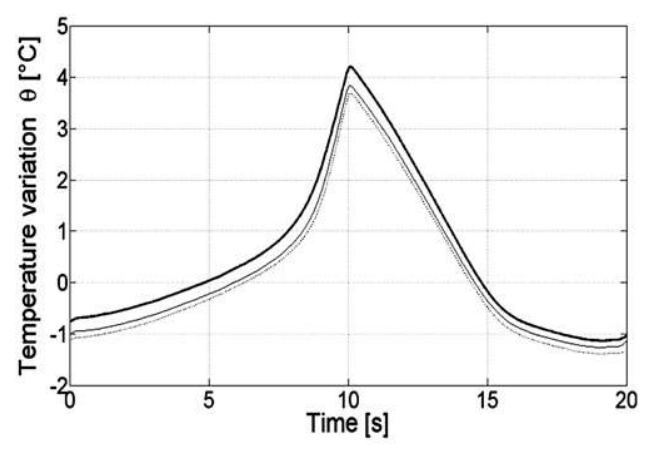

(b) Temperature variation during the three cycles at $\pm 300 \mathrm{~mm} / \mathrm{min}$

Fig. 10. Temperature variation for three cycles at $\lambda_{3}=6$ for two loading rates. Solid thick line $=$ cycle 1 , solid thin line $=$ cycle 2 , dotted line $=$ cycle 3 .

$\pm 100 \mathrm{~mm} / \mathrm{min}$ ). Consequently, stabilization occurs with a greater number of cycles.

Fig. 10 presents the temperature variation obtained for the third set of three cycles $\left(\lambda_{3}=6\right)$. These curves exhibit some major differences compared to those obtained for smaller maximum stretch ratios $\left(\lambda_{1}\right.$ and $\left.\lambda_{2}\right)$. Fig. 10 (a) shows a great increase in temperature variation of around $3{ }^{\circ} \mathrm{C}$ during loading at time $t=25 \mathrm{~s}$ (again, the time scale was initialized at the beginning of each cycle). Two reasons can explain that this phenomenon is due to crystallization. First, crystallization is a strong exothermic phenomenon. Second, the stretch ratio at time $t=25 \mathrm{~s}$ is close to the stretch ratio usually considered for the beginning of crystallization. Fig. 10 (a) and (b) show that the stabilized regime is nearly obtained from the second cycle for both cases (the difference between the temperature at the beginning and at the end of a cycle is small from the second cycle onwards).

Fig. 11 presents the temperature variation obtained for the fourth set of three cycles $\left(\lambda_{4}=7.5\right)$. The great increase in temperature is once more observed starting from a stretch ratio close to the value usually considered for the beginning of crystallization. It can also be observed that the temperature rate slightly decreases at the end of each loading phase. Two factors may explain this phenomenon: either heat exchanges with the outside of the specimen, or a decrease in the crystallization rate, as shown in Ref. [33]. Only an analysis based on heat source calculation can provide the explanation. This will be presented in the companion paper [28]. Following the same reasoning as above, Fig. 11 (a) and (b) show that the stabilized regime is reached from the second cycle for the two loading rates tested (the second and third loading curves are almost superimposed).
Fig. 12 proposes another view of the previous results. In the diagrams, the temperature variations are plotted as a function of the stretch ratio for the four sets of three cycles in the case of a loading rate equal to $\pm 300 \mathrm{~mm} / \mathrm{min}$. For the cycles at $\lambda_{1}=2$, inferior to $\lambda_{\mathrm{c}}$, the temperature during loading is higher than that during unloading at a given stretch ratio (see Fig. 12 (a)). This is due to the non-adiabatic conditions of the test. For the cycles at $\lambda_{2}=5$, close to $\lambda_{c}$, a hysteresis loop in the plane $(\lambda, \theta)$ begins to form, from $\lambda$ equal to 4.2 (see Fig. 12 (b)). The fact that the temperature at the beginning of unloading is higher than that at the end of loading proves that the kinetics of crystallization and of crystallite melting are different. The fact that this phenomenon is observed if the maximum stretch ratio is superior to $\lambda_{\mathrm{c}}$ is the signature of strain-induced crystallization. As the maximum stretch ratio of the cycles increases, the area of the hysteresis loop increases (compare Fig. 12 (b) and (c)). This means that the level of crystallinity reached during the cycles at $\lambda_{3}=6$ has increased compared to the cycles at $\lambda_{2}=5$. Finally, for the cycles at $\lambda_{4}=7.5$ (see Fig. 12 (d)), two hysteresis loops are observed. The fact that the slope of the temperature variation curve decreases before the end of loading could mean that the crystallinity rate decreases. Consequently, heat production due to crystallization is lower than the heat given to the outside of the specimen. This explains why the temperature at the beginning of unloading is lower than that at the end of loading. Then the second hysteresis loop observed, for which the temperature during unloading is higher than that during loading, is explained by the same considerations as for lower stretch ratios. It should finally be noted that the temperature variation for the highest maximum stretch ratio applied reaches $10{ }^{\circ} \mathrm{C}$.

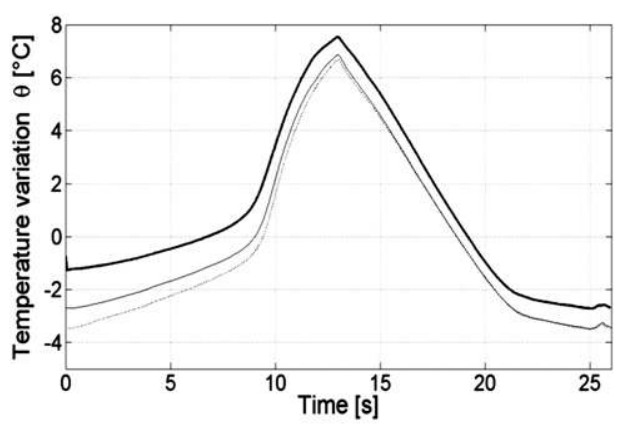

(b) Temperature variation during the three (a) Temperature variation during the three
cycles at $\pm 100 \mathrm{~mm} / \mathrm{min}$

(a) Temperature variation during
cycles at $\pm 100 \mathrm{~mm} / \mathrm{min}$

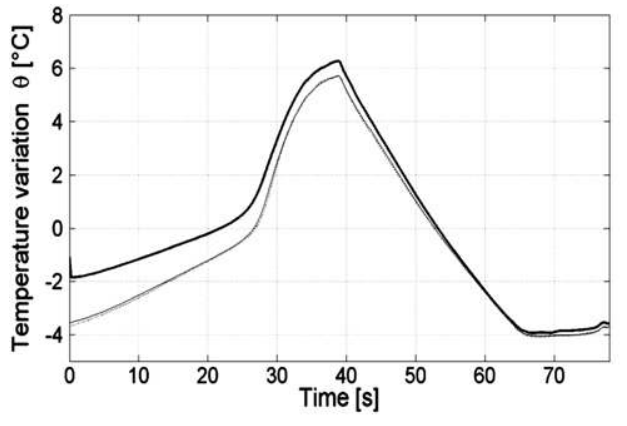

\section{cycles at $\pm 300 \mathrm{~mm} / \mathrm{min}$}




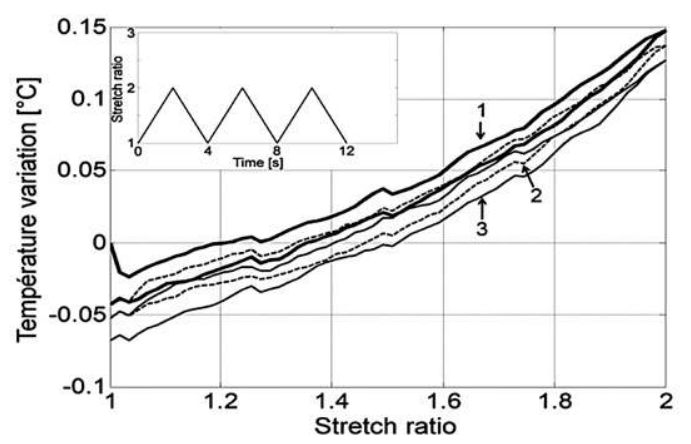

(a) $\lambda_{1}=2$

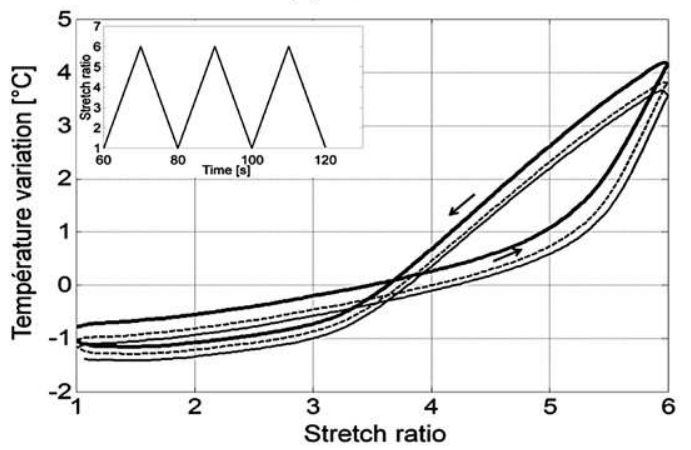

(c) $\lambda_{3}=6$

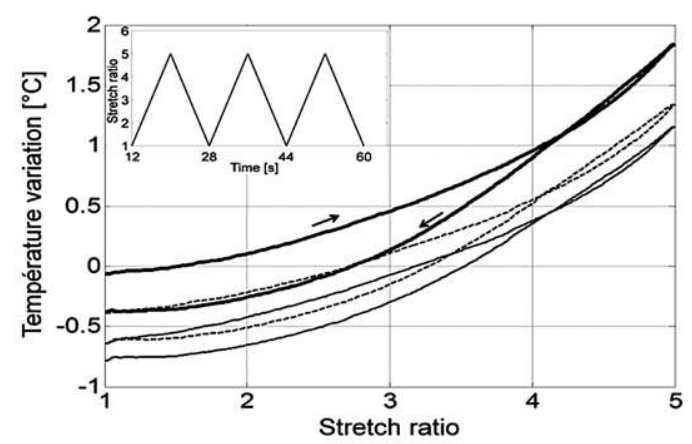

(b) $\lambda_{2}=5$

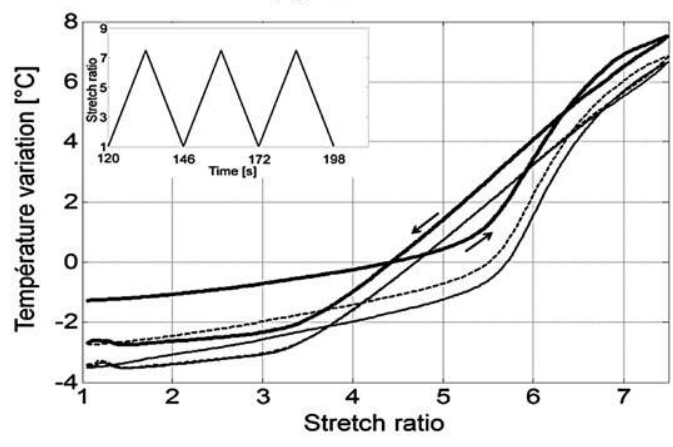

(d) $\lambda_{4}=7.5$

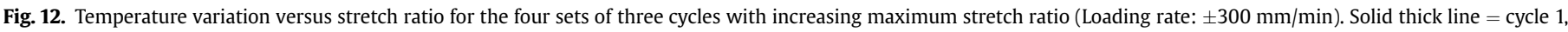
solid thin line $=$ cycle 2 , dotted line $=$ cycle 3 .

These last results show that thermal measurements provide additional information that is not available from the strain-stress relationships.

\subsection{Loading-unloading test with pauses}

\subsubsection{Mechanical response}

Fig. 13 shows that during the loading pauses, the stress relaxes if the stretch ratio applied is higher than $\lambda_{c}$. Upon unloading, the stress does not significantly evolve whatever the fixed strain. The fact that stress relaxation is observed only if the stretch ratio is superior to that at which crystallization begins is in good

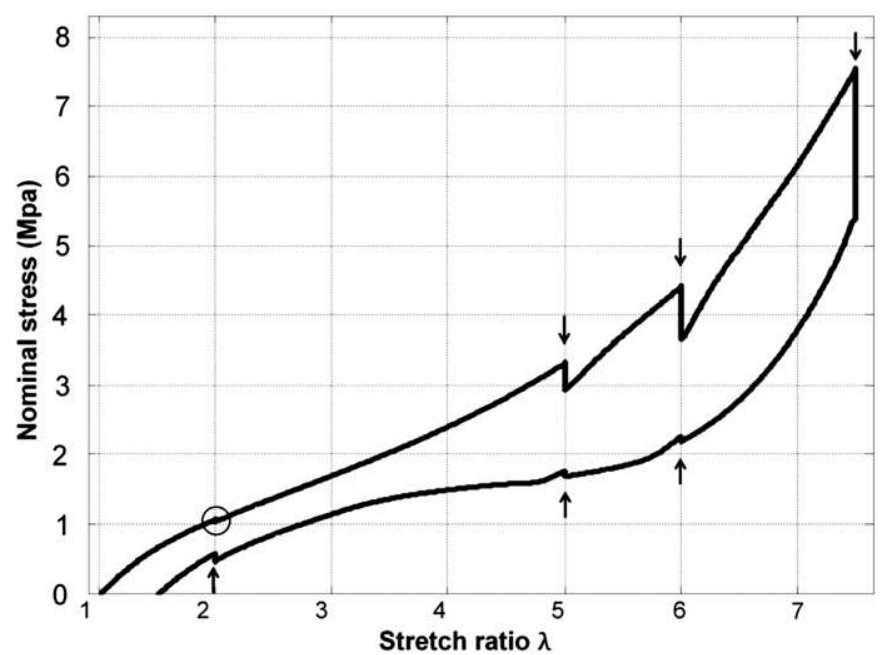

Fig. 13. Nominal stress versus stretch ratio during the loading-unloading test with pauses. agreement with the results obtained by Refs. [6,34]. Moreover, the fact that no significant evolution in stress is observed during unloading seems to highlight a difference in the kinetics of crystallization and crystallite melting. More precisely, crystallite melting is classically assumed to be instantaneous compared to crystallization. Finally, the residual stretch ratio obtained at the end of the mechanical cycle is nearly equal to 1.5 . This value is much higher than that obtained during the cyclic test (1.1, see Fig. 5). This result could be explained by the fact that the effect of internal stresses due to entanglements in the material network (topological stresses) is altered by the successive relaxation steps.

\subsubsection{Thermal response}

The thermal measurements performed during the test provide complementary information about the processes of crystallization and crystallite melting.

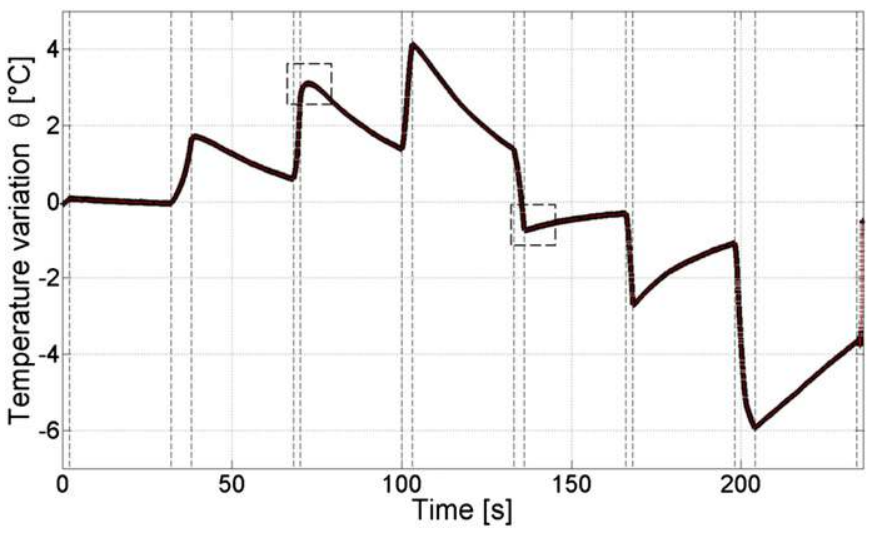

Fig. 14. Temperature variation measured during the loading-unloading test with pauses 


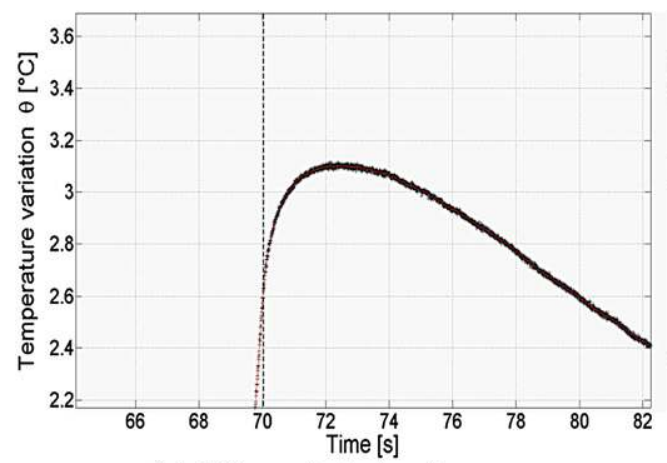

(a) $100 \mathrm{~mm} / \mathrm{min}$ loading rate

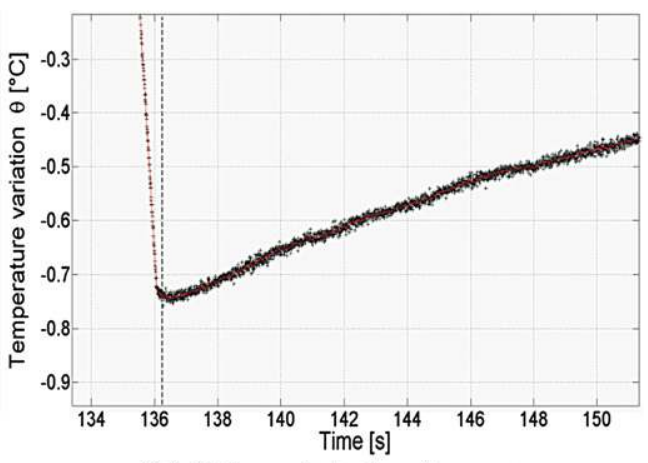

(b) $300 \mathrm{~mm} / \mathrm{min}$ loading rate

Fig. 15. Magnification of dotted boxed zones in Fig. 15.

Fig. 14 presents the temperature variation $\theta$ versus time. The value of $\theta$ varies between $-6{ }^{\circ} \mathrm{C}$ and $4{ }^{\circ} \mathrm{C}$. Let us now examine the loading and the unloading successively:

(i) During the loading phase: the temperature variation $\theta(t)$ is always positive during the successive loading phases, and tends to return to zero when the stretch ratio is kept constant. It is worth noting that, if the applied stretch ratio is higher than $\lambda_{c}$, the temperature continues to increase for a few seconds before decreasing. This can be shown in Fig. 15 (a). It is to be noted that the phenomenon is not observed for stretch ratios inferior to $\lambda_{c}$. As thermoelastic coupling cannot explain this phenomenon and as viscosity is not observed in the material under study, the fact that the crystallinity continues is the only explanation for this increase in temperature (crystallization is a strong exothermic phenomenon). It can be noted that similar phenomena have also been observed in metallic materials subjected to first-order phase transformation (accompanied by latent heat production) [35].

(ii) During the unloading phase: the temperature variation $\theta(\mathrm{t})$ is always negative during the successive unloading phases, and tends to return to the ambient temperature when the stretch ratio remains constant (see Fig. 14). Contrary to loading, no "out-of-phase" phenomenon is observed for pauses at stretch ratios superior to $\lambda_{c}$, as shown in Fig. 15 (b). This observation confirms the kinetic difference between crystallization and crystallite melting.

\section{Conclusion}

This paper investigates the thermal response associated with deformation processes in unfilled natural rubber. For this purpose, cyclic and stress relaxation tests were performed. Temperature variations measured by infrared camera were analysed during loading, unloading and stress relaxation for the stretch ratio range in which crystallization occurs.

Temperature variations were measured at low frequency, typically inferior to $1 \mathrm{~Hz}$. Results show that the entropic behaviour of natural rubber leads to heat production (absorption) during loading (unloading). The thermal response is found to provide additional information on deformation processes, more particularly with respect to strain-induced crystallization. Indeed, a significant temperature increase is observed when strain-induced crystallization occurs, and the temperature evolution shows that the kinetics of crystallization and of crystallite melting are different. Nevertheless, due to the heat exchange between the specimen and its environment, temperature variation is not the most relevant quantity to link the thermal response to the change in the microstructure. More particularly, temperature variation does not enable us to characterize separately thermomechanical couplings and mechanical dissipation. As a consequence, it is difficult to compare satisfactorily the model predictions with temperature measurements. This is the reason why the calculation of heat sources from the temperature measurement is certainly a new route to revisit to improve the analysis presented in the present paper. The companion paper [28] focuses on the analysis of heat source evolution for the same tests.

\section{Acknowledgements}

Authors acknowledge the "Manufacture Française des pneumatiques Michelin" for supporting this study. Authors also thank D. Berghezan, F. Vion-Loisel and E. Munch for the fructuous discussions.

\section{References}

[1] Mullins L. Rubber Chemistry and Technology 1948;21:281-300.

[2] Chagnon G, Verron E, Gornet L, Marckmann G, Charrier P. Journal of the Mechanics and Physics of Solids 2004;52:1627-50.

[3] Payne A. Journal Applied Polymer Science 1962;19:53-7.

[4] Fletcher WP, Gent AN. Trans. Institute of the Rubber Industry 1953;29:266-80

[5] Stringfellow R, Abeyaratne R. Materials Science and Engineering: A 1989;112: 127-31.

[6] Le Cam JB, Toussaint E. Macromolecules 2008;41:7579-83.

[7] Le Cam JB, Toussaint E. Mechanics of Materials 2009;41:898-901.

[8] Toki S, Fujimaki T, Okuyama M. Polymer 2000;41:5423-9.

[9] Toki S, Sics I, Ran S, Liu L, Hsiao B, Murakami S, et al. Macromolecules 2002;35: 6578-84.

[10] Trabelsi S, Albouy PA, Rault J. Macromolecules 2002;35:10054-61.

[11] Trabelsi S, Albouy PA, Rault J. Macromolecules 2003;36:9093-9.

[12] Huneau B. Rubber Chemistry and Technology 2011;84:425-52.

[13] Albouy PA, Guillier G, Petermann D, Vieyres A, Sanseau O, Sotta P. Polymer 2012;53:3313-24.

[14] Tosaka M, Senoo K, Sato K, Noda M, Ohta N. Polymer 2012;53:864-72.

[15] Candau N, Chazeau L, Chenal JM, Gauthier C, Ferreira J, Munch E, et al. Polymer 2012;53:2540-3.

[16] Gough J. Proc Lit and Phil Soc Manchester, 2nd, ser 1805;vol. 1288.

[17] Joule JP. Phil Mag 4th 1857;14:227.

[18] Mars WV, Fatemi A. International Journal of Fatigue 2002;24:949-61.

[19] Mars WV. Rubber Chemistry and Technology 2002;75:1-17.

[20] Le Cam JB. Ph.D. thesis, 2005.

[21] Saintier N, Cailletaud G, Piques R. International Journal of Fatigue 2006;28: 530-9.

[22] Chrysochoos A, Louche $H$. International Journal of Engineering Science 2000;38:1759-88.

[23] Chrysochoos A, Louche H. Materials Science \& Engineering. A, Structural Materials: Properties, Microstructure and Processing 2001;307:15-22.

[24] Chrysochoos A, Huon V, Jourdan F, Muracciole J-M, Peyroux R, Wattrisse B. Strain 2010;46:117-30.

[25] Pottier T, Moutrille MP, Le Cam JB, Balandraud X, Grédiac M. Experimental Mechanics 2009;49:561-74 
[26] Le Cam JB. Strain 2011;48:174-88

[27] Toussaint E, Balandraud X, Le Cam JB, Grédiac M. Polymer Testing 2012;31: 916-25.

[28] Samaca Martinez JR, Le Cam JB, Balandraud X, Toussaint E, Caillard J, Polymer, in press, http://dx.doi.org/10.1016/j.polymer.2013.03.012

[29] Sakagami T, Nishimura T, Yamaguchi T, Kubo N, Nihon Kikai Gakkai Ronbunshu AH. Transactions of the Japan Society of Mechanical Engineers 2006;72:1853-9.

[30] Schlosser P. PhD thesis, 2008.
[31] Chrysochoos A, Wattrisse B, Muracciole JM, Kaim YE. Journal of Mechanics of Materials and Structures 2009;4:245-62.

[32] Balandraud X, Toussaint E, Le Cam J-B, Grédiac M, Behnke R, Kaliske M. In: Jerrams S, Murphy N, editors. Constitutive Models for Rubber VII. CRC Press; 2012. p. $45-50$.

[33] Flory PJ. The Journal of Chemical Physics 1947;15:397-408.

[34] Marchal J. Ph.D. thesis, 2006.

[35] Balandraud X, Ernst E, Soos E. Zeitschrift fur Angewandte Mathematik und Physik 2000;51:419-48. 16 